\title{
Crosstalk Between Nuclear Glucose- Regulated Protein 78 and Tumor Protein 53 Contributes to the Lipopolysaccharide Aggravated Apoptosis of Endoplasmic Reticulum Stress-Responsive Porcine Intestinal Epithelial Cells
}

\author{
Qian Jiang ${ }^{a, b}$ Gang Liu ${ }^{a, c, d} \quad$ Jiashun Chen ${ }^{a, d} \quad K^{2}$ Yang Yao ${ }^{a, c, d} \quad$ Yulong Yinn ${ }^{a, c, d}$ \\ aKey Laboratory of Agroecological Processes in Subtropical Region, Institute of Subtropical Agriculture, \\ Chinese Academy of Sciences, National Engineering Laboratory for Pollution Control and Waste \\ Utilization in Livestock and Poultry Production, Changsha, bUniversity of the Chinese Academy of \\ Sciences, Beijing, 'Taoyuan Agro-ecosystem Research Station, Soil Molecular Ecology Section, Institute \\ of Subtropical Agriculture, Chinese Academy of Sciences, Changsha, ${ }^{d}$ College of Animal Science and \\ Technology, Hunan Agricultural University, Changsha, China
}

\section{Key Words}

Endoplasmic reticulum stress $\bullet$ IPEC-J2 • GRP78 • P53 • Inflammation • LPS

\begin{abstract}
Background/Aims: Lipopolysaccharides (LPSs) act as virulence factors that trigger intestinal inflammation and thereby compromise the production of pigs worldwide. Intestinal diseases and dysfunction have been attributed to endoplasmic reticulum stress (ERS) and the subsequent apoptosis of intestinal epithelial cells. Therefore It is important to explore whether LPSs aggravate ERS-mediated apoptosis of intestinal epithelial cells. Methods: ERS and inflammation models were established in porcine cell line J2 (IPEC-J2) and the cells were treated with tunicamycin or LPS at specific times. The expression of marker proteins was determined by western blot and immunofluorescence. Possible crosstalk between proteins was analyzed by co-immunoprecipitation. Small interfering RNA transfection was employed to verify the mechanisms. Results: We found that Escherichia coli-derived LPS aggravated ERS and ERS-mediated apoptosis in ERS-responsive IPEC-J2 cells. The crosstalk between nuclear glucose-regulated protein 78 (GRP78) and tumor protein 53 (p53) was verified to trigger this LPS-aggravated apoptosis of ERS-responsive intestinal cells. Conclusion: This novel finding implies that intestinal malfunctions might solely originate from the effects of Gram-negative
\end{abstract}

\begin{tabular}{ll}
\hline Kang Yao & Key Laboratory of Agroecological Processes in Subtropical Region, Institute of Subtropical Agriculture \\
Chinese Academy of Sciences, Changsha, Hunan (China) \\
E-Mail yaokang@isa.ac.cn
\end{tabular}




\section{Cellular Physiology Cell Physiol Biochem 2018;48:2441-2455 \\ \begin{tabular}{ll|l} 
DOI: 10.1159/000492682 & $\begin{array}{l}\text { O } 2018 \text { The Author(s). Published by S. Karger AG, Basel } \\
\text { www.karger.com/cpb }\end{array}$ \\
\hline and Biochemistry
\end{tabular}}

Jiang et al.: LPS Aggravates Apoptosis via Crosstalk Between GRP78 and P53

bacteria on ERS-responsive intestinal cells. The regulation of ERS signaling (especially the crosstalk between nuclear GRP78 and p53) in ERS-responsive/rapidly growing intestines may help intestinal cells survive from Gram-negative bacterial infections.

(C) 2018 The Author(s)

Published by S. Karger AG, Basel

\section{Introduction}

The endoplasmic reticulum (ER) is responsible for polypeptide synthesis, posttranslational modification, and the folding of peptides to form proteins for cellular functions or secretion. Endoplasmic reticulum stress (ERS) occurs normally in the rapidly growing intestines of piglets when excessive misfolded and unfolded proteins accumulate in the ER lumen. Such stress triggers a series of signaling and transcriptional events known as the unfolded protein response (UPR). Although the UPR attempts to restore homeostasis in the ER, failure can lead to local inflammation of stressed cells and programmed cell death via apoptosis or autophagy $[1,2]$. The UPR consists of three main signaling branches: inositolrequiring enzyme 1 -a, protein kinase RNA-like endoplasmic reticulum kinase (PERK), and activating transcription factor 6 (ATF6). Prolonged or uncontrolled ERS results in apoptosis. Phosphorylated eukaryotic initiation factor $2 \alpha$ (p-eIF2 $\alpha$ ) can enhance the translation of ATF4, a transcription factor that participates in the oxidative stress response and ER stressinduced apoptosis [3]. The subsequent release of glucose-regulated protein 78 (GRP78), PERK auto-phosphorylation, and phosphorylation of, for example, eukaryotic initiation factor $2 \alpha($ eIF $2 \alpha)$ can lead to the attenuation of caspase-mediated translation, which regulates genes involved in ERS/CHOP-induced apoptosis.

ERS is associated with cancer [4], diabetes [5], and cystic fibrosis [6], as well as infectious and inflammatory diseases [7, 8]. Inflammatory bowel disease (IBD) is a chronic, globally occurring gastrointestinal disorder and a major cause of dyspepsia and diarrhea [9]. Using mouse models, together with the phenotype of IBD and IBD genetic data, researchers have improved our understanding of the importance of ERS and related pathways in intestinal inflammation [10]. The intestinal epithelial cells have a critical role in the innate immune response against pathogenic bacteria. In addition to acting as a physical barrier, these cells generate signals by producing several cytokines, chemokines, and other signaling molecules [11-13]. In addition, our previous experiment found that the ERS is normally triggered in the rapidly growing intestine, and Escherichia coli infection aggravates CHOP-mediated apoptosis mainly in the jejunal epithelial tissue of weaning stressed piglets [14]. The intestinal porcine epithelial cell (IPEC) line IPEC-J2, originally isolated from jejunal epithelia of an unsuckled neonatal piglet, is a realistic and representative tool for mimicking the jejunal epithelial tissue of piglets $[15,16]$. In the fields of veterinary medicine and animal science, it serves as a good cell model for pharmacological research as well as studies of toxicity, microbiology, bioavailability, and metabolism. These previous studies prompted us to investigate the potential effect of mild inflammation on ERS and ERS-mediated apoptosis in IPEC-J2.

E. coli infections compromise the efficiency of pigs and pork production, and thus regulation of the inflammation and associated cell death might be effective methods of improving the profitability of the porcine industry [17]. Lipopolysaccharide (LPS) is a component in the outer membrane of Gram-negative bacteria and is recognized by epithelial toll-like receptor-4 [18]. Treatment with LPS results in the activation of nuclear factor (NF)$\kappa B$ and subsequent upregulation of proinflammatory cytokines including interleukin (IL)- $1 \alpha$, IL-1 $\beta$, and IL-6 [19]. Previous studies using the IPEC-J2 cell line have established a model of inflammation using Salmonella enterica-derived LPS [18, 20]. However, there are few reports on inflammatory models based on E. coli-derived LPS in intestinal epithelial cells. Here, we selected $E$. coli-derived LPS to produce an inflammatory milieu, and used tunicamycin (TUNI) to develop an ERS-induced apoptosis model with IPEC-J2 cell line. Our goal was to investigate the effect of $E$. coli-derived LPS-induced mild inflammation on ERS-responsive intestinal epithelial cells and determine whether crosstalk occurs between inflammation and ERS. 


\section{Cellular Physiology Cell Physiol Biochem 2018;48:2441-2455 \begin{tabular}{ll|l} 
and Biochemistry Published online: 16 August, 2018 & $\begin{array}{l}\text { (c) } 2018 \text { The Author(s). Published by S. Karger AG, Basel } \\
\text { www.karger.com/cpb }\end{array}$
\end{tabular}}

Jiang et al.: LPS Aggravates Apoptosis via Crosstalk Between GRP78 and P53

\section{Materials and Methods}

\section{Reagents}

Fetal bovine serum (FBS), Dulbecco's modified Eagle medium (DMEM) and antibiotics (penicillin and streptomycin) for the cell cultures were obtained from Gibco (Carlsbad, CA, USA). Plastic culture plates were manufactured by Corning Inc. (Corning, NY, USA). Cell counting Kit-8 (CCK-8) and Nuclear and Cytoplasmic Protein Extraction Kit were purchased from Beyotime Biotechnology (Shanghai, China). The E. coli serotype 055:B5-derived LPS, TUNI, and dimethyl sulfoxide (DMSO) were purchased from Sigma Aldrich (St. Louis, MO, USA), and the antibodies against p53, p65, caspase 12, CHOP, mTOR, GRP78, p-eIF2 $\alpha$, eIF2 $\alpha$, H3, and $\beta$-actin, plus the CytoPainter ER Staining Kit-Red Fluorescence, were obtained from Abcam (Cambridge, MA, USA).

\section{Cell culture, ERS, and inflammation induction}

IPEC line IPEC-J2, originally isolated from jejunal epithelia of an unsuckled neonatal piglet, was cryopreserved with liquid nitrogen in the Key Laboratory of Agro-ecological Processes in Subtropical Region. IPEC-J2 cells of passages 4 to 6 were used in this study. Cells were grown in DMEM containing 10\% FBS, 50 $\mu \mathrm{g} \mathrm{mL} \mathrm{L}^{-1}$ penicillin, and $50 \mu \mathrm{g} \mathrm{mL}^{-1}$ streptomycin and seeded on 6-well plates (Corning, Inc.) at a density of 100,000 cells per well for $48 \mathrm{~h}$ before being washed with phosphate buffered saline (PBS). The cell culture procedures were performed as described in a previous study [21]. DMSO was used to dilute TUNI and an equal amount was added to the control group. To generate ERS-induced apoptosis, we determined that 1.0 $\mu \mathrm{g} \mathrm{mL} \mathrm{m}^{-1}$ TUNI for $24 \mathrm{~h}$ was the most appropriate time through preliminary experiments. To optimize the $E$. coli-derived LPS concentration and time required for inducing mild inflammation, we replaced the original medium with an FBS-free culture medium supplemented with $0,0.5,1.0$ or $2.0 \mu \mathrm{g} \mathrm{mL}^{-1}$ E. coli-derived LPS. After $24 \mathrm{~h}$ treatment, cell growth was monitored with CCK-8 according to the manufacturer's instructions. Based on the induction model of ERS and inflammation, we treated cells with DMSO, $1 \mu \mathrm{g} \mathrm{mL}^{-1} \mathrm{TUNI} / \mathrm{DMSO}$, $0.5 \mu \mathrm{g} \mathrm{mL} \mathrm{m}^{-1} \mathrm{LPS} / \mathrm{DMSO}$, or combinations of TUNI/LPS to investigate the crosstalk between inflammation and ERS.

\section{Monitoring of inflammatory cytokines}

Weconducted enzyme-linked immunosorbentassays (ELISAs) with an IL-6 monoclonal captureantibody and the biotinylated polyclonal secondary antibody IL-6 Duoset (DY206E; R\&D Systems, Minneapolis, MN, USA), according to the manufacturer's instructions. Briefly, amplifications were performed in horseradish peroxidase-conjugated streptavidin and then visualized using a colorimetric 3, 3',5, 5'-tetramethylbenzidine substrate (Sigma-Aldrich). The reaction was terminated by the addition of $2 \mathrm{~N}$ sulfuric acid. Optical density was measured at $450 \mathrm{~nm}$ with an HT Synergy plate reader coupled to Gen 5 software (Biotech Instruments, Inc., Winooski, VT, USA). Purified recombinant IL-6 protein was used to generate a standard curve to assess the approximate concentrations. The level of IL- 6 was determined by normalization to purified IL- 6 protein standards. Similar steps were taken to determine the concentration of IL-8.

\section{Staining to examine ER fluorescence}

After the treatments with or without LPS or TUNI, the ER fluorescence of line IPEC-J2 was stained by the CytoPainter ER Staining Kit-Red Fluorescence according to the manufacturer's protocol. Co-localization with the EGFP-calreticulin signal demonstrated selectivity for the endoplasmic reticulum. Briefly, cells were plated on glass culture dishes, using four replications per treatment. After $24 \mathrm{~h}$, the cells were washed with PBS, and ER- and nuclear fluorescence-staining was performed according to the manufacturer's instructions. Cells were observed under a laser confocal microscope (FV1000; Olympus, Tokyo, Japan), using an excitation wavelength of $370 \mathrm{~nm}$ and a scattering wavelength of $460 \mathrm{~nm}$.

\section{Flow cytometry analysis}

After the treatments, the cells were collected and apoptosis was analyzed by flow cytometry using an Annexin V-FITC Apoptosis Detection Kit (Beyotime Biotech, Shanghai, China) according to the manufacturer's instructions. Data acquisition and analysis were performed using the flow cytometry system and CellQuest 


\section{Cellular Physiology Cell Physiol Biochem 2018;48:2441-2455

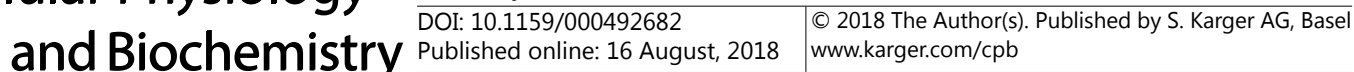

Jiang et al.: LPS Aggravates Apoptosis via Crosstalk Between GRP78 and P53

software (BD Biosciences, Franklin Lakes, NJ, USA). Statistical analyses of mortality and apoptosis rates were performed with Prism v5.0 software (GraphPad Software, La Jolla, CA, USA) based on output results via flow cytometry.

\section{Western blot analysis}

The IPEC-J2 cells from LPS or TUNI treatments were cultured for different times in 6-well plates. Samples were lysed for $10 \mathrm{~min}$ in ice-cold buffer with a complete protease inhibitor cocktail. For the specific analysis involving subcellular fractionation, nuclear or cytoplasmic proteins were extracted by Nuclear and Cytoplasmic Protein Extraction Kit according to the protocols. Immunoblotting assays were performed as described previously [22]. The blots were examined with the ECL Plus detection system (Thermo Fisher Scientific, Waltham, MA, USA) under conditions recommended by the manufacturer, and the signals were visualized on Fujifilm (LAS-3000; Fuji, Tokyo, Japan). The protein band densities were normalized to the $\beta$-actin/H3 signal and quantified by Quantity One software (Bio-Rad, Hercules, CA, USA).

\section{Immunofluorescence}

Cells were fixed and permeabilized with cold $100 \%$ methanol for 10 min on ice. For staining, they were treated with $4 \mathrm{~N} \mathrm{HCl}$ for $10 \mathrm{~min}$, followed by $1.5 \mathrm{M}$ Tris- $\mathrm{HCl}(\mathrm{pH} 8.8)$ for $10 \mathrm{~min}$, before being blocked with $1 \%$ bovine serum albumin. Cells were then incubated overnight at $4{ }^{\circ} \mathrm{C}$ with primary anti-GRP78 rabbit polyclonal antibody and subsequently incubated for $1 \mathrm{~h}$ with Alexa Fluor 488-conjugated secondary antibodies (Life Technologies, Carlsbad, CA, USA). Cells were washed three times and the ER and nuclei were stained with CytoPainter ER Staining Kit-Red Fluorescence according to the instructions. Images were captured by a laser confocal microscope.

\section{Co-immunoprecipitation}

IPEC-J2 cells after LPS or TUNI treatments were cultured for various times in 6-well plates. All samples were gently lysed for $10 \mathrm{~min}$ in ice-cold buffer with a complete protease inhibitor cocktail. The coimmunoprecipitation (Co-IP) assays were conducted according to the instructions supplied with the Co-IP kit (Pierce, Waltham, USA). For this study, we used either GRP78 (78KD) or p53 (53KD) antibodies to coimmunoprecipitate p53 (53KD) or GRP78 (78KD) protein, respectively. After IPEC-J2 cells were pre-treated with LPS or TUNI, as well as combination of LPS and TUNI for $24 \mathrm{~h}$, lysed supernatants were used as input control. The negative control received the same concentration of GRP78 (78KD)/p53 (53KD) antibody, except that the coupling resin was replaced with control agarose resin, which is not amine-reactive. sodium dodecyl sulfate polyacrylamide gel electrophoresis and western blot were conducted to evaluate the protein bands. Data acquisition and analysis were performed with Image Lab system and software (Bio-Rad).

\section{Transfection with small interfering RNA}

In order to investigate whether the p53 complex (according to the results of Co-IP) disturbed GRP78 redistribution in the cells, control small interfering RNA (siRNA) and siRNAs that target p53 genes were purchased from the ABI Silencer® Select Pre-Designed \& Validated siRNA collection (Applied Biosystems, Carlsbad, CA). The IPEC-J2 line was transfected with a Nucleofector T Kit (Lonza, Basel, Switzerland) using a siRNA pool containing $1 \mu \mathrm{mol}$ of each siRNA or $4 \mu \mathrm{mol}$ of the control siRNA. After $48 \mathrm{~h}$, the transfected cells were washed with PBS.

\section{Statistical analysis}

Mean values \pm SD of three independent experiments were calculated in Excel 2010 (Microsoft, San Francisco, CA USA). Statistical analysis was performed with Prism 5.0 software (GraphPad Software) using one-way analysis of variance. This was followed by Bonferroni multiple comparisons and post hoc analysis. Differences among the treatments were considered statistically significant when $\mathrm{P}<0.01\left({ }^{* *}\right)$ or $\mathrm{P}<0.05\left(^{*}\right)$. 


\section{Cellular Physiology Cell Physiol Biochem 2018;48:2441-2455 \begin{tabular}{ll|l} 
and Biochemistry Published onlıne: 16 August, 2018 & $\begin{array}{l}\text { (c) } 2018 \text { The Author(s). Published by S. Karger AG, Basel } \\
\text { www.karger.com/cpb }\end{array}$
\end{tabular}

\section{Results}

\section{TUNI treatment led to ER stress and apoptosis in IPEC-J2}

We exposed IPEC-J2 cells to $1 \mu \mathrm{g} \mathrm{mL} \mathrm{L}^{-1}$ TUNI to induce ERS. Treatment for 8-32 h significantly reduced cell growth and induced ERS markers CHOP and GRP78 in a timedependent manner (Fig. 1A, B). Flow cytometry analysis indicated that $24 \mathrm{~h}$ of TUNI exposure increased the rate of cell apoptosis (Fig. 1C). We also examined ER morphology via red fluorescence staining, and the results showed that $32 \mathrm{~h}$ of TUNI treatment caused a "cavity" in the ER (Fig. 1D), which indicated an accumulation of unfolded proteins in the ER lumen. Moreover, the fluorescence intensity of calreticulin in the TUNI-treated cells was lower than in normal cells in the control group. These data demonstrated that our ER stress model was successfully established in line IPEC-J2.

\section{E. coli-derived LPS induced an inflammatory milieu in IPEC-J2}

IPE-J2 cells treated with E. coli-derived LPS $\left(0.5\right.$ to $\left.2.0 \mu \mathrm{g} \mathrm{mL}{ }^{-1}\right)$ for $24 \mathrm{~h}$ showed significantly lower cell viability (Fig. 2A, B) and increased secretion of IL-6 and IL-8 (Fig. 2C, D) in a dose-dependent manner. Furthermore, the upregulation of nuclear p65 and caspase 12 and decreased level of Bcl-2 provided evidence of the inflammatory milieu induced by LPS. Examination of ER morphology via fluorescence staining showed that treatment with $0.5 \mu \mathrm{g} \mathrm{mL} \mathrm{H}^{-1} \mathrm{LPS}$ for $24 \mathrm{~h}$ did not cause a morphological "cavity" or affect the fluorescence intensity (Fig. 2I). Therefore, we selected a low concentration $(0.5$ $\mu \mathrm{g} \mathrm{mL}^{-1}$ ) of $E$. coli-derived LPS to explore the effect of mild inflammation on ERSmediated apoptosis.

The inflammatory milieu activated strong ERS-mediated apoptosis in ERS-responsive IPEC-J2, possibly via p53 up-regulation

We measured cell viability via CCK-8 (Fig. 3B) and flow cytometry (Fig. 3 D, E), and found that the rate of apoptosis was highly increased following treatment with LPS plus TUNI (Fig. 3 D, E). However, the inflammatory cytokines (IL-6 and IL-8) and p65 expression (Fig. 3 C, I) were not further elevated by dual treatment compared with LPS treatment alone. This suggested that the addition

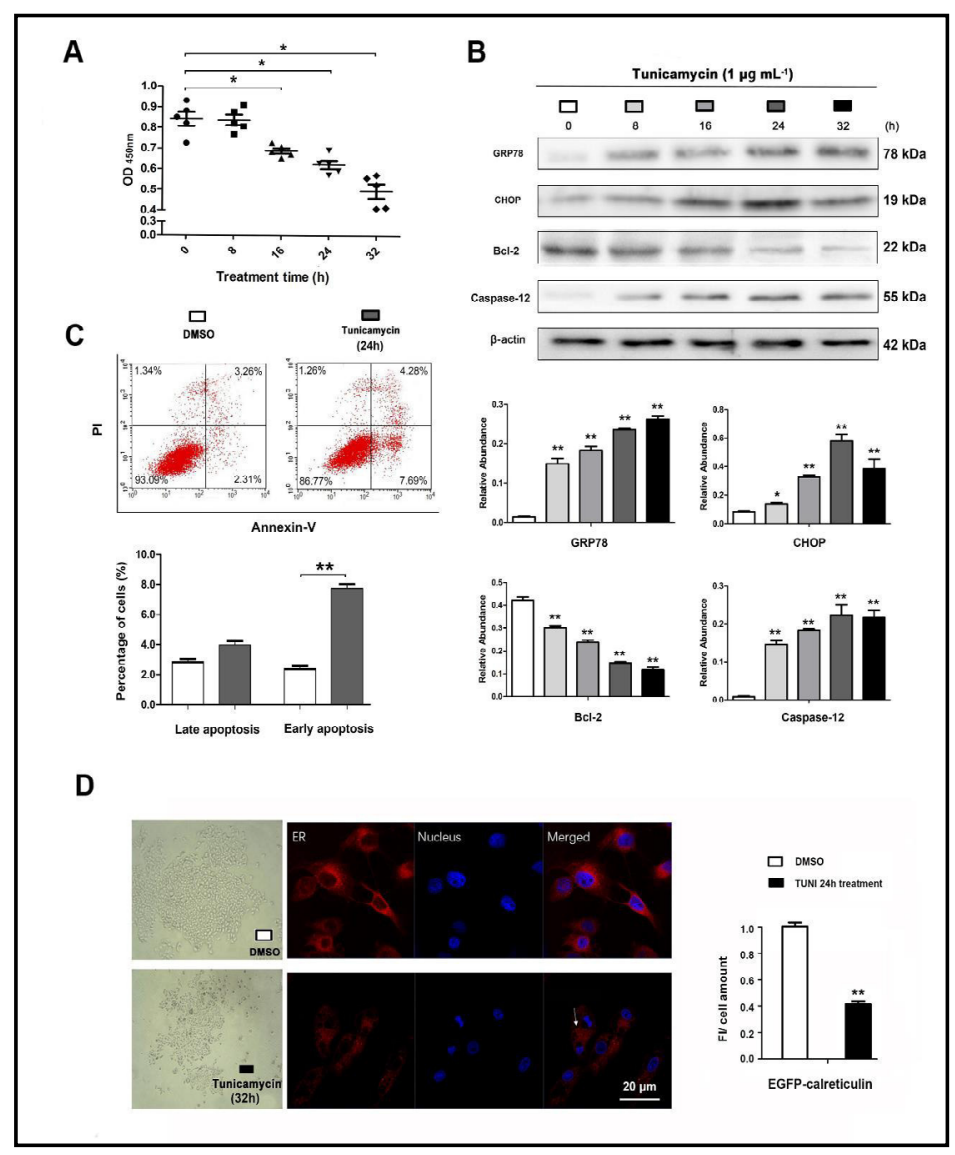

Fig. 1. TUNI-induced ERS and apoptosis in IPEC-J2 cells. A) Cell viability assay performed by CCK-8 after cells were treated with 1.0 $\mu \mathrm{g} \mathrm{mL} \mathrm{L}^{-1}$ TUNI for 0-32 h. B) Western blot analysis of ERS and apoptotic pathway proteins after ERS induction. C) Cell apoptosis assay using flow cytometry on cells treated with TUNI for $24 \mathrm{~h}$. D) ER- and nuclear fluorescence-staining of cells treated with DMSO or TUNI $\left(1 \mu \mathrm{g} \mathrm{mL}{ }^{-1}\right)$ for $32 \mathrm{~h}$. 
Fig. 2. LPS-induced inflammation and apoptosis in IPEC-J2 cells. A) Cell morphology in an optical microscope $(200 \times)$. B) Viability assay performed by CCK-8 after cells were treated with LPS $(0.5$ $2.0 \mu \mathrm{g} \mathrm{mL} \mathrm{m}^{-1}$ ) for $24 \mathrm{~h}$. C, D) Levels of IL- 6 and IL- 8 secreted in culture medium were determined by ELISA after cells were treated with LPS ( $\left.0.5 \mu \mathrm{g} \mathrm{mL}^{-1}\right)$ for $24 \mathrm{~h}$. E) Western blot analysis of nuclear p65, Bcl-2, and caspase 12 proteins after inflammation was induced. F) Relative abundance of nuclear p65. G) Relative abundance of Bcl-2. H) Relative abundance of caspase- 12 . I) ER- and nuclear fluorescencestaining of cells treated with DMSO or LPS $\left(0.5 \mu \mathrm{g} \mathrm{mL}^{-1}\right)$ for $24 \mathrm{~h}$.

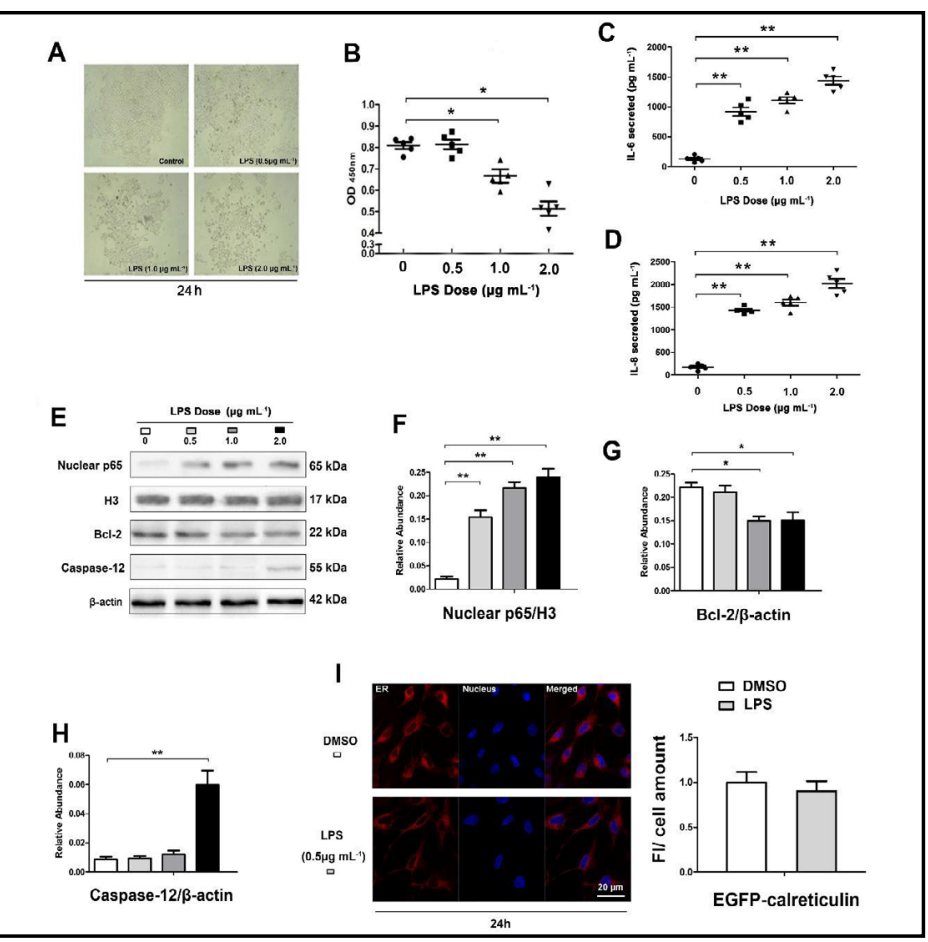

Fig. 3. Exacerbation of TUNIinduced apoptosis by LPS in IPEC-J2 cells. Cells were treated for $24 \mathrm{~h}$ with DMSO, LPS $\left(0.5 \mu \mathrm{g} \mathrm{mL}^{-1}\right)$, TUNI $\left(1 \mu \mathrm{g} \mathrm{mL}^{-1}\right)$, or a combination of LPS and TUNI. A) Cell morphology in an optical microscope (200x). B) Cell viability assay performed by CCK8 after the treatments. C) Levels of IL- 6 and IL- 8 secreted by cells. D) Percentage of late apoptotic cells. E) Percentage of early apoptotic cells. F) Western blot analysis of ERS and NF- $\kappa B$ pathway proteins. G) Relative abundance of p-eIF $2 \alpha$. H) Relative abundance of CHOP. I) Relative abundance of nuclear p65. J) Relative abundance of nuclear p53.

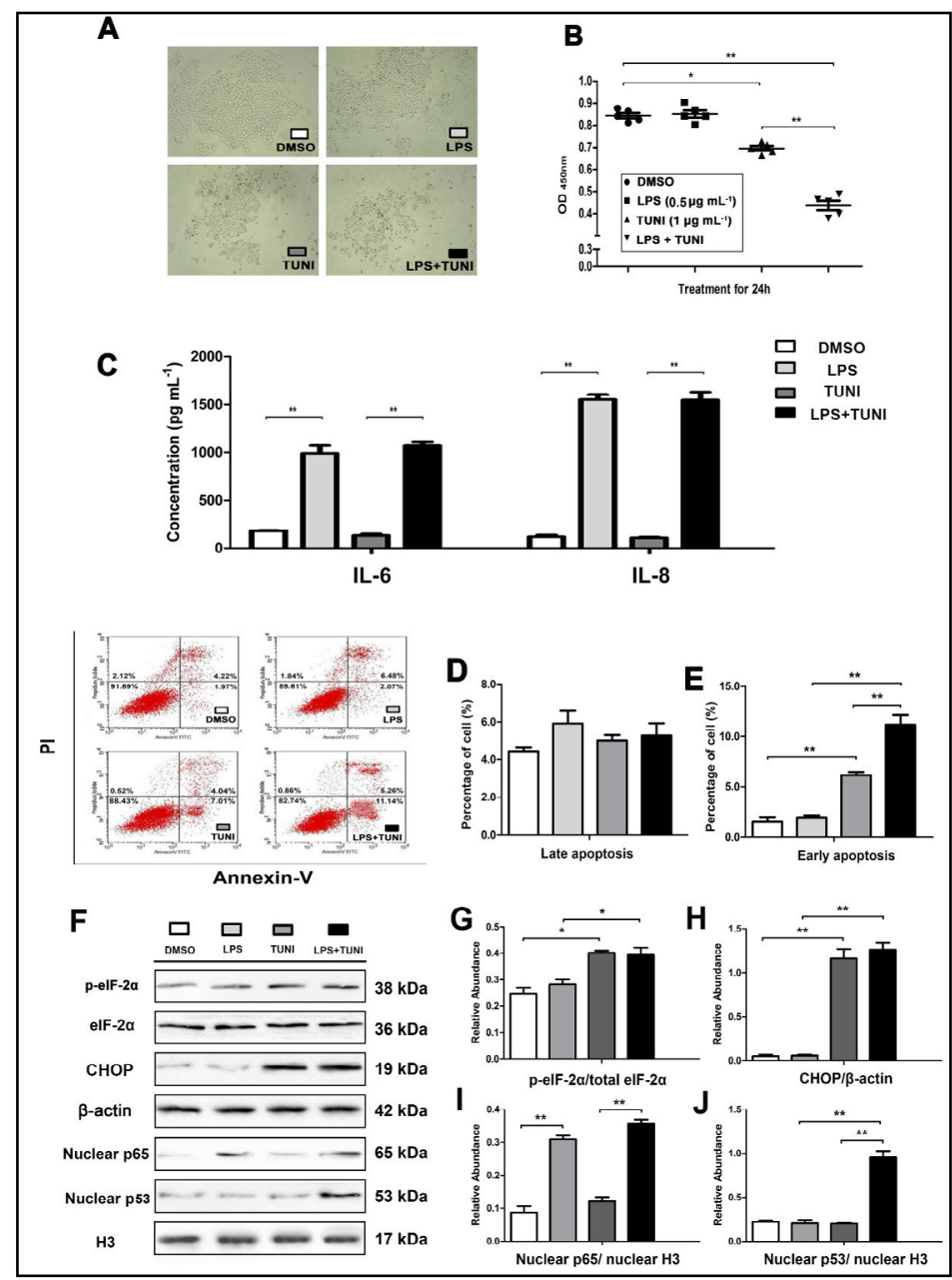


of TUNI did not induce an additional inflammatory response to aggravate cell apoptosis. Western blotting was conducted to determine the expression of proteins in the ERS and NF- $\kappa \mathrm{B}$ pathways (Fig. 3F). Dual treatment with LPS and TUNI did not increase the expression of nuclear p65 compared with LPS treatment only (Fig. 3I). However, it highly increased the levels of nuclear p53 compared with single treatments (Fig. 3J). Moreover, the levels of p-eiF2a and CHOP were up-regulated in response to TUNI-induced ERS, but not by LPS (Fig. 3G, H). The data implied that the NF- $\kappa B$ component had no effects on the upstream pathway of TUNI-induced ERS, but $\mathrm{NF}-\mathrm{kB}$-mediated nuclear p53 may play a key role in the execution phase of apoptosis.

\section{The inflammatory milieu altered subcellular localization and the expression of GRP78 in ERS- responsive IPEC-J2 cells}

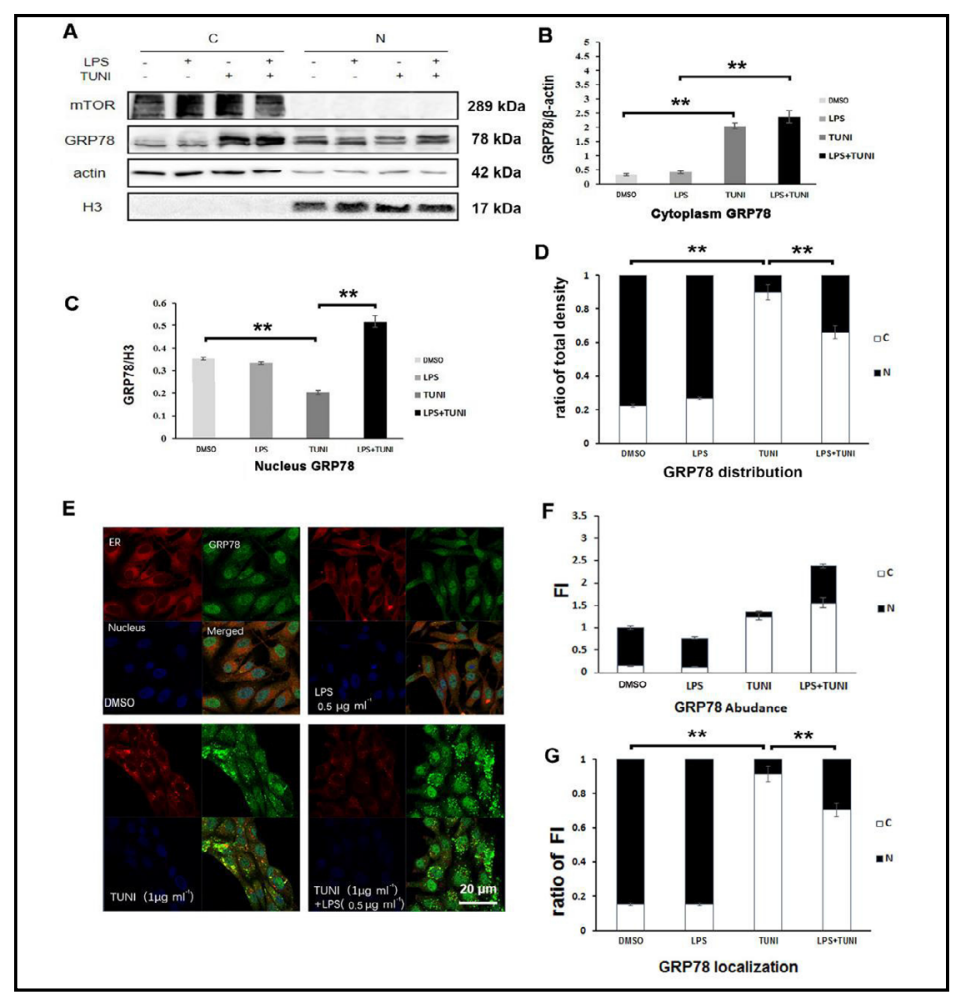

Fig. 4. Interference by LPS of GRP78 redistribution in ERS-responsive Line IPEC-J2. Cells were treated with DMSO, LPS $\left(0.5 \mu \mathrm{g} \mathrm{mL}^{-1}\right)$, TUNI ( $1 \mu \mathrm{g} \mathrm{mL}^{-1}$ ), or a combination of LPS and TUNI for $24 \mathrm{~h}$. A) Western blot analysis of cytoplasmic and nuclear mTOR, GRP78, $\beta$-actin, and H3 proteins after nucleocytoplasmic separation (mTOR was used as indicator of separating efficiency). B, C) Relative band abundance of GRP78 in cytoplasm and nucleus, respectively. D) Cellular sublocalization of GRP78. E) ER (red/EGFP-calreticulin), GRP78 (green), and nuclei (blue) were stained by immunofluorescence. F) Fluorescent abundance of cytoplasmic (C) and nuclear (N) GRP78. G) Relative FI ratio of cytoplasmic (C) to nuclear (N) GRP78 in cells.

GRP78 is thought to be located mainly in the cytoplasm, especially in the ER [23]. However, as a molecular chaperone, GRP78 shuttles between the nucleus and the cytoplasm, interacting with several molecules to regulate many biochemical pathways. Our subcellular localization analysis positioned GRP78 mainly in the nuclei of IPEC-J2 cells within the normal environment, and TUNI-induced ERS markedly increased distribution of GRP78 in the cytoplasm, while it decreased that in the nuclei (Fig. 4B, C, F). Moreover, the inflammatory milieu induced by LPS increased the level of nuclear GRP78 by three-fold in ERS-responsive cells (Fig. 4 C, F), implying that NF- $\kappa$ B or a component interfered with GRP78 subcellular localization (Fig. 4D, G). We found it interesting that this phenomenon occurred only in ERS-responsive cells, whereas single treatment with LPS had no effect on the subcellular localization of GRP78 in the single inflammatory environment. These results suggested, therefore, that GRP78 shuttling might play a key role in the crosstalk between inflammation and the ERS pathway. Compared with the other three groups, the level of ER- fluorescence/ EGFP-calreticulin was markedly decreased by LPS and TUNI dual treatment (Fig. 4E), indicating that degradation of the ER or degeneration of its normal function occurred. Based on these results, we believe that further analyses of the ERS pathway and NF- $\mathrm{BB}$ proteins are required to elucidate the physiological function of GRP78 in these potential interactions.

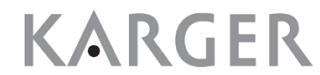


Fig. 5. Co-immunoprecipitation of GRP78 and p53 after the specific treatments. A, C, E) GRP78 (78KD) antibody to co-immunoprecipitate p53 (53KD) after cells were treated with both LPS and TUNI (A), LPS treatment alone (C), or TUNI treatment alone (E). B, D, F) p53 (53KD) antibody to coimmunoprecipitant GRP78 (78KD) after cells were treated with both LPS and TUNI (B), LPS alone (D), or TUNI alone (F). After IPEC-J2 cells were pre-treated for $24 \mathrm{~h}$, lysed supernatant was used as the input control. Negative control (-ve ctrl) received the same concentration of GRP78/p53 antibody except that the coupling resin was replaced with control agarose resin, which is not amine-reactive.

Fig. 6. Redistribution of GRP78 in ERS-responsive IPEC-J2 cells recovered by p53 knockdown. After cells were pre-treated with control-SiRNA or p53-SiRNA for 48 $h$, they were incubated with DMSO or a combination of LPS and TUNI for $24 \mathrm{~h}$. A) Cell viability assays performed by CCK-8. B) Western blot analysis of cytoplasmic GRP78 and $\beta$-actin, nuclear p53, GRP78, and $\mathrm{H} 3$ proteins after nucleocytoplasmic separation. C, D, E) Relative band abundance of cytoplasmic GRP78 and nuclear p53. F) ER (red), GRP78 (green), and nucleus (blue) were stained by cell immunofluorescence. G) Fluorescent abundance of cytoplasmic (C) and nuclear (N) GRP78. H) Relative FI ratio of cytoplasmic (C) to nuclear (N) GRP78 in cells.
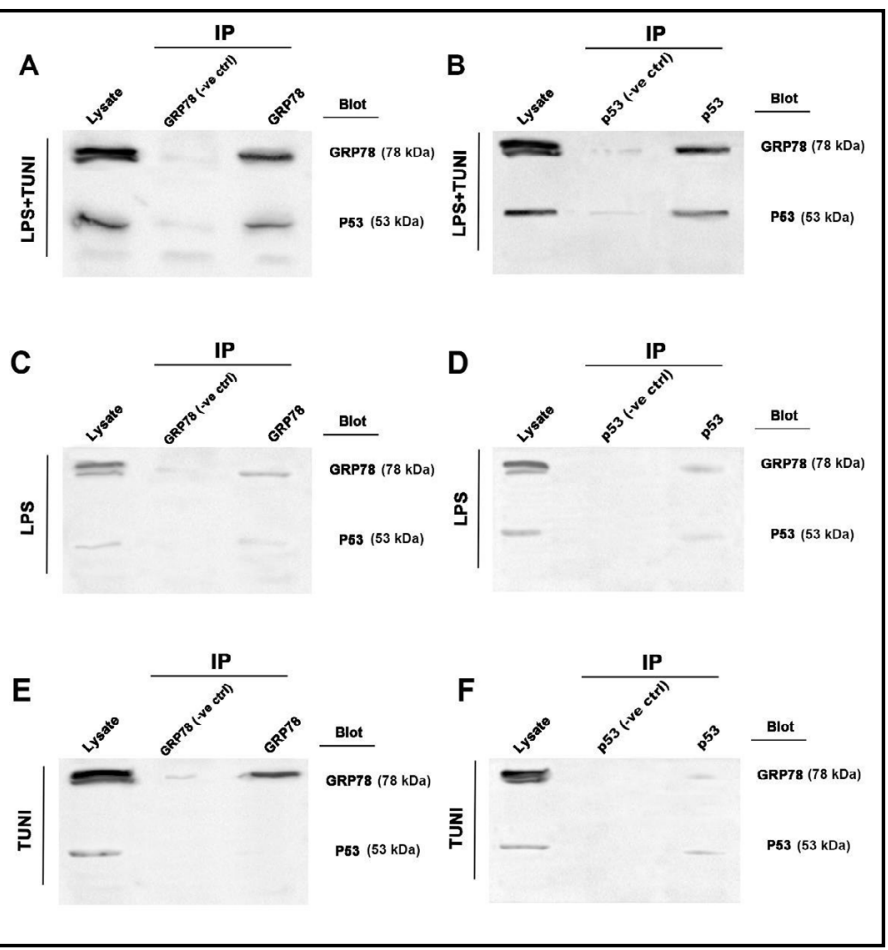

A

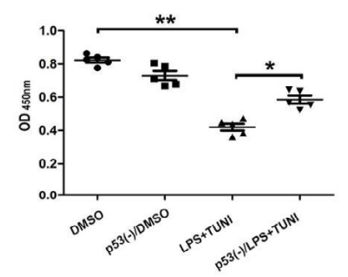

B

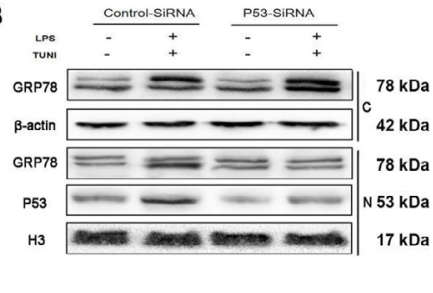

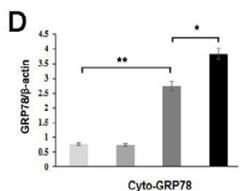

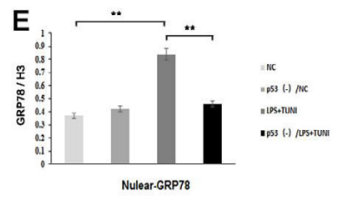

$\mathrm{F}$

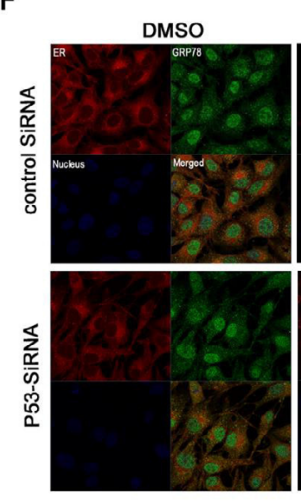

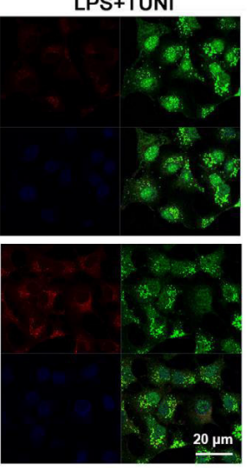

LPS+TUNI
G
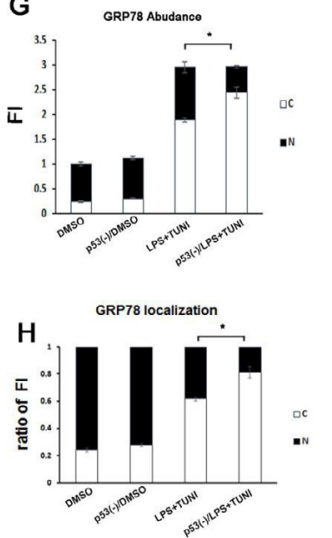


\section{Cellular Physiology Cell Physiol Biochem 2018;48:2441-2455

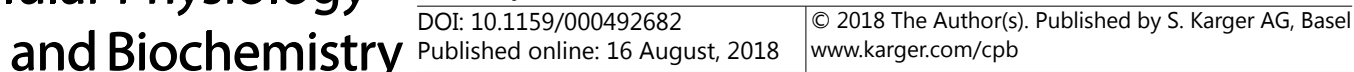

p53 knockdown recovers the TUNI-induced redistribution of GRP78 from the nucleus to the ER lumen

As described in Section 3.3, dual treatment with LPS and TUNI did not affect the expression of nuclear p65 any more than the LPS single treatment. However, it greatly increased the level of nuclear p53 compared with the single treatments. To investigate the mechanism of GRP78 redistribution induced by dual treatment with LPS and TUNI, we used Co-IP to examine potential interactions between GRP78 and p53. This enabled us to verify the relationship between nuclear p53 and GRP78. As shown, crosstalk between p53 and GRP78 was observed in the dual-treated cells (Fig. 5A, B) and in cells treated with LPS alone (Fig. 5C, D). However, no crosstalk effects between p53 and GRP78 were observed in cells that were treated with TUNI alone (Fig. 5E, F). The p53 tumor suppressor is a nuclear protein that regulates transcription and mediates several biological processes, such as growth arrest, senescence, and apoptosis in response to various forms of stress [24, 25]. Depending upon the experimental conditions, ERS can facilitate either a reduction $[26,27]$ or an increase in p53 activity [28,29]. Because p53 can modulate the functions of the ER in response to stress [30], we transfected siRNAs targeting p53 genes into IPEC-J2 cells to verify whether they could interfere with the redistribution of GRP78 under our experimental conditions. Forty-eight hours after transfection, p53-targeting siRNAs $(1 \mu \mathrm{mol})$ reduced the expression of p53 by $52 \%$ compared with control-siRNAs $(4 \mu \mathrm{mol})$. The transfected cells were then treated with both LPS and TUNI. Knockdown of p53 led to three outcomes: 1) cell death was attenuated (Fig. 6A); 2) TUNI-induced redistribution of GRP78 from the nucleus to the ER lumen was recovered (Fig. 6D, E, H); and 3) the ER-fluorescence/EGFP-calreticulin was recovered (Fig. 6F). These results provided evidence that the interactive effect between inflammation and ERS was attenuated by p53 knockdown.

\section{Discussion}

We present a spontaneous cell model of ERS resulting from TUNI treatment. The inflammation induced by LPS appeared to be a key element in ERS-mediated apoptosis, indicating possible pathogenesis and damage when intestinal cells are infected by Gramnegative bacteria. Our results indicated that the inflammatory milieu is a promotive but not primary component of the ERS response. First, the mild inflammation that was induced by treatment with $0.5 \mu \mathrm{g} \mathrm{mL}^{-1} \mathrm{LPS}$ had little influence on normal cells but severely impaired cell viability, altered the subcellular localization, and changed the expression levels of GRP78 in ERS-responsive IPEC-J2 cells. Second, knockdown of p53 attenuated the collaboration of LPS and TUNI by preventing an interaction between GRP78 and p53 in the nucleus.

\section{Endoplasmic reticulum stress in intestinal epithelial cells}

Although abundant data from studies of animal models and human bowel diseases [31-34] have demonstrated the importance of the ERS pathway in the intestines, especially in the goblet cells [35], little is known about the role of ERS in intestinal epithelial cells, which play critical roles in gut defenses and nutrient absorption. The efficiency of nutrient absorption and utilization is largely determined by the condition of these cells. Intestinal epithelial cells grow rapidly in pigs and are responsible for the synthesis of nutritional transporters throughout the animal's lifespan. Furthermore, reports have revealed that ERS can be induced or resolved [34, 36-39], including in line IPEC-1 cells [40]. The intestinal epithelium is naturally exposed to pathogenic bacteria, acts as a physical barrier, and plays a significant role in generating signals through the production of inflammatory cytokines and ERS-responsive signaling molecules. Therefore, line IPEC-J2 is a realistic and representative tool for in-vitro studies of ERS and inflammation. 


\section{Cellular Physiology Cell Physiol Biochem 2018;48:2441-2455

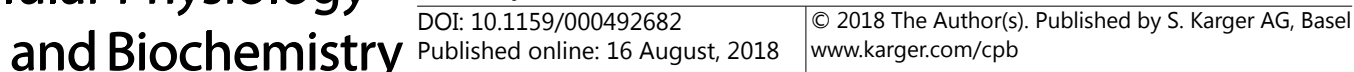

Jiang et al.: LPS Aggravates Apoptosis via Crosstalk Between GRP78 and P53

\section{TUNI and ERS}

TUNI triggers stress by inhibiting N-linked glycosylation of newly synthesized proteins in the ER [41]. Glycosylation is essential for controlling both the processing and quality of protein folding. If hydrophobic parts of the amino acid chain cannot be buried in the interior of the protein during folding, GRP78 is recruited to bind these regions to prevent the aggregation of unfolded proteins [42]. Accordingly, researchers have reported that TUNI can induce ERS in various organs belonging to different animal species [43-46]. However, only rarely have those studies focused on porcine intestinal cells. We found that the addition of TUNI induced spontaneous ERS in a time-dependent manner. Although the milieu and homeostasis are different between cell models and animal intestines, ERS-correlated proteins were significantly increased by treatment with TUNI in this in vitro model; this result is similar to that of ERS in porcine intestines. Therefore, we propose that this new ERS cell model of porcine intestinal cells could be applied to investigate the molecular mechanism of ERS and ERS-mediated biological processes. To our knowledge, this is the first time that TUNI has been used to induce ERS in IPEC-J2 cells.

\section{Apoptosis and ERS}

Prolonged or severe ERS can result in premature apoptosis via intrinsic or factor associated suicide (Fas)-mediated pathways [47]. The classical intrinsic pathway of apoptotic cell death involves an altered balance between apoptotic inhibitors (Bcl2 family) and pro-apoptotic proteins (Bax, Bak), which leads to the release of cytochrome c from the mitochondria, activation of caspases, and intracellular-controlled degradation [48]. However, the most important pro-apoptotic pathway involving the ERS-response is PERK activationtriggered and ATF4-mediated production of transcription factor CHOP (or GADD153). ERS can also initiate apoptosis by specifically activating caspase-12, which is mainly located in the ER. A previous study [49] demonstrated increased expression of capase-12 and CHOP in response to the dual environments of ERS and infection. Likewise, we found that TUNI treatment increased the apoptosis of IPEC-J2, while it up-regulated the expression of CHOP. The apoptotic response is dependent upon both the condition of the cells and the context of the stress. Our results demonstrated that the mild inflammatory environment markedly increased the amount of apoptosis in ERS-responsive cells, which is in contrast with a previous report [50]. This discrepancy might have arisen because the regulation of ERS-induced apoptosis is influenced not only by the severity, nature, and duration of the stressor-as well as the activation of various UPR elements-but also by the expression of critical pro- and anti-apoptotic proteins that are based on cell type.

\section{GRP78 and the inflammatory milieu}

The GRP78 protein is a central regulator of the UPR and is considered a representative ERS marker. When stress occurs, GRP78 is released from branches of the UPR-PERK, IRE1-a, and ATF6-and binds misfolded proteins, thereby activating the UPR. In addition, CHOP is a major stress-inducible pro-apoptotic gene that participates in ERS-induced apoptosis. The activation of CHOP can be regulated by all three branches. Increased GRP78 expression has also been reported in human IBD patients in a previous study [9], which suggested that specific impairment of the ERS response induces inflammation in the gut. In contrast, our data pointed to unresolved ER stress-induced apoptosis as a cause of apoptotic damage, rather than as a reason for inflammation. Notably, apoptosis can be largely instigated by an inflammatory milieu. Our results implied that intestinal inflammation induced by Gramnegative bacteria might primarily worsen gut damage through ERS-mediated cell apoptosis. GRP78 is thought to be located mainly in the cytoplasm, especially in the ER and many factors, such as inflammation, might lead to upregulation of GRP78. Our results suggest that GRP78 acts as a molecular chaperone, shuttling between the nucleus and the cytoplasm and interacting with several molecules to regulate many biochemical pathways. The addition of $0.5 \mu \mathrm{g} \mathrm{mL}{ }^{-1}$ LPS had little influence on the expression and subcellular location of GRP78 in normal IPEC-J2 cells; however, LPS significantly affected the expression and subcellular 


\section{Cellular Physiology Cell Physiol Biochem 2018;48:2441-2455

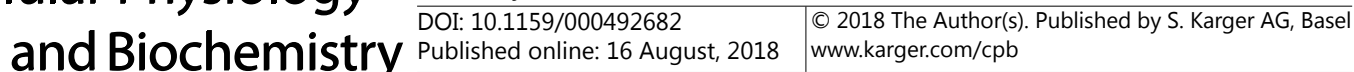

localization of GRP78 in ERS-responsive cells. One might speculate that the inflammatory environment interferes with the pathways mediated by GRP78, particularly those moving towards either apoptosis or salvage, and thus contributes to the development of intestinal damage.

\section{Crosstalk between ERS and inflammation}

Links have been verified between ERS and both local and systemic inflammation, suggesting that stress itself promotes inflammation. However, little is known about how inflammation affects ERS-induced apoptosis. Cancer research has focused on the instigation of ERS-induced apoptosis in tumors [51], providing evidence for the importance of ERS in apoptotic regulation. Even under normal conditions, organs that are highly efficient protein synthesizers are challenged by ERS and ERS-induced apoptosis, including the liver [52], mammary glands [53], and intestines [54]. NF- $\kappa \mathrm{B}$ is considered central to intestinal inflammation, and can be activated by pathogenic bacteria, thus the intestine is naturally exposed to the co-effects of NF- $\kappa B$ and ERS. ERS may trigger NF- $\kappa B$ activation through the following different pathways: 1) IRE1-a, complexes with IкB kinase (IKK) via the adaptor protein TRAF2 can lead to the degradation of Ik-B $\alpha$ [55]; 2) PERK initiates the blockage of Ik$\mathrm{B} \alpha$ translation [56]; 3) cytoplasmic GRP78 directly interacts with IKK complex [57]; and 4) $\mathrm{Ca}^{2+}$ metabolism and the production of reactive oxygen species is disturbed in various organs [58]. We tested the relationship between ERS and inflammation/infection by treating cells with DMSO, TUNI/DMSO, LPS/DMSO, or combinations of TUNI/LPS. The expression of key proteins in the ERS pathways, inflammation, and apoptosis was monitored via western blots while inflammatory cytokines were evaluated by ELISAs. When ERS was induced by TUNI, there was no influence on the secretion of inflammatory cytokines and p65 expression, which indicated the ineffectiveness of them in promoting inflammation. Because this outcome differed from that previously reported from in-vivo examinations, we might speculate that cell cultures treated with TUNI alone either cannot trigger or they lack the activation factor that initiates inflammation. When ERS is induced by TUNI, it can trigger the upregulation of cytoplasmic GRP78 and the PERK-CHOP pathway [59,60], which is consistent with our results. We found that the inflammatory milieu induced by LPS promoted apoptosis in responsive cells and altered the subcellular localization of GRP78. However, it is difficult to clarify the primary function. We could hypothesize that NF- $\kappa B$ activation interrupts the UPR, leading to a compensatory increase in GRP78 levels. Nevertheless, this hypothesis cannot fully explain the inhibitory effect that LPS appeared to have on the redistribution of GRP78 from the nucleus to the ER lumen. To investigate the interaction between those two factors, we used Co-IP to examine possible interactions between GRP78 and IKK- $\alpha$, IKK- $\beta$, and p53 complex. Co-interaction of nuclear p53 and GRP78 was observed in the dual (combination of LPS and TUNI)treated cells and LPS only treated cells. Moreover, this co-interaction was not detected under TUNI treatment alone. Knockdown of p53 recovered the TUNI-induced redistribution of GRP78 from the nucleus to the ER lumen,

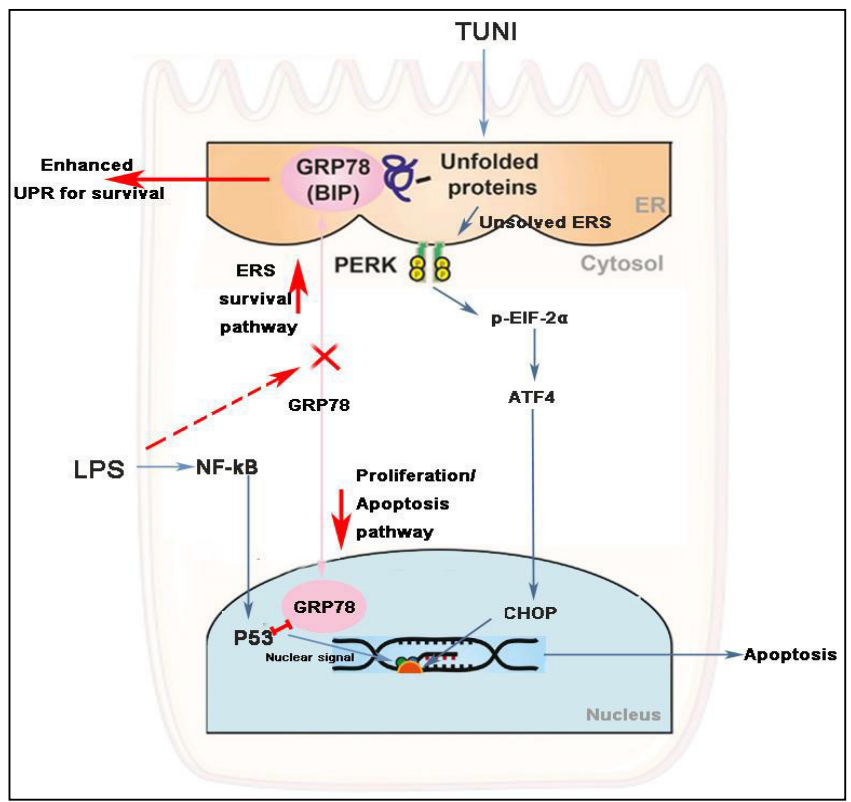

Fig. 7. Working model of GRP78 arresting in the nucleus in a dual environment of inflammation and ER. 


\section{Cellular Physiology Cell Physiol Biochem 2018;48:2441-2455 \begin{tabular}{ll|l} 
DOI: 10.1159/000492682 & $\begin{array}{l}\text { O } 2018 \text { The Author(s). Published by S. Karger AG, Basel } \\
\text { www.karger.com/cpb }\end{array}$ \\
\hline and Biochemistry
\end{tabular}}

and ameliorated cell apoptosis by blocking the crosstalk between inflammation and ERS in stress-responsive cells. It is acknowledged that p53 and p65 show competitive binding to $\mathrm{CBP} / \mathrm{p} 300$ (a nuclear integrator of nuclear factor-kappa B and p53 signaling). When inflammation is triggered, CBP is highly activated by phosphorylation, increases binding p65, and thus exposes higher levels of unconjugated p53 [61]. This has been considered classic crosstalk between nuclear p65 and p53 in the NF- $\kappa \mathrm{B}$ pathway. We proposed a model (Fig. 7) to illustrate how the LPS-induced inflammatory milieu triggers ERS-induced apoptosis through activation of p53 to arrest GRP78 in the nucleus.

As more pathways are implicated in intestinal diseases and disorders, the recognition of ERS-induced apoptosis and its association with the inflammatory environment will enable researchers to identify pathways that are particularly important for the pathogenesis of infections. Our findings suggested that crosstalk between nuclear GRP78 and p53 contributed to the LPS promoted apoptosis in ERS-responsive porcine IPEC-J2/rapidly growing intestine cells, indicating that intestinal disorders may solely originate from the effect of Gramnegative bacteria on the ERS-responsive intestine. This novel finding implied that regulation of the ERS response in the rapidly growing intestine may help intestinal cells survive Gramnegative bacteria infections. Future work is warranted to explore the optional nutrients for the regulation of ERS (especially the crosstalk between nuclear GRP78 and p53) and exploit feeding products to improve the intestinal health of growing piglets.

\section{Acknowledgements}

This work was supported by the National Science Foundation for Distinguished Young Scholars of Hunan Province (2016JJ1015), the National Natural Science Foundation of China (31472107, 31470132, 31702126), the Chinese Academy of Sciences 'Hundred Talent' award, and the Open Foundation of Key Laboratory of Agro-ecological Processes in Subtropical Region, Institute of Subtropical Agriculture, Chinese Academy of Sciences (ISA2016101).

This article does not refer to any studies with human participants or animals performed by any of the authors.

\section{Disclosure Statement}

The authors declare that there are no conflicts of interest regarding the research and publication of this article.

\section{References}

1 Lee WS, Yoo WH, Chae HJ: ER Stress and Autophagy. Curr Mol Med 2015;15:735-745.

-2 Cheung YT, Zhang NQ, Hung CH, Lai CS, Yu MS, So KF, Chang RC: Temporal relationship of autophagy and apoptosis in neurons challenged by low molecular weight beta-amyloid peptide. J Cell Mol Med 2011;15:244-257.

-3 Ma X, Dai Z, Sun K, Zhang Y, Chen J, Yang Y, Tso P, Wu G, Wu Z: Intestinal Epithelial Cell Endoplasmic Reticulum Stress and Inflammatory Bowel Disease Pathogenesis: An Update Review. Front Immunol 2017;8:1271.

4 Calgarotto AK, da Silva Pereira GJ, Bechara A, Paredes-Gamero EJ, Barbosa CM, Hirata H, de Souza Queiroz ML, Smaili SS, Bincoletto C: Autophagy inhibited Ehrlich ascitic tumor cells apoptosis induced by the nitrostyrene derivative compounds: Relationship with cytosolic calcium mobilization. Eur J Pharmacol 2012;678:6-14.

5 Sari FR, Watanabe K, Thandavarayan RA, Harima M, Zhang S, Muslin AJ, Kodama M, Aizawa Y: 14-3-3 Protein Protects Against Cardiac Endoplasmic Reticulum Stress (ERS) and ERS-Initiated Apoptosis in Experimental Diabetes. J Pharmacol Sci 2010;113:325-334. 


\section{Cellular Physiology Cell Physiol Biochem 2018;48:2441-2455 \begin{tabular}{ll|l} 
and Biochemistry Published online: 16 August, 2018 & $\begin{array}{l}\text { (c) } 2018 \text { The Author(s). Published by S. Karger AG, Basel } \\
\text { www.karger.com/cpb }\end{array}$
\end{tabular}}

Jiang et al.: LPS Aggravates Apoptosis via Crosstalk Between GRP78 and P53

White MM, Geraghty P, Hayes E, Cox S, Leitch W, Alfawaz B, Lavelle GM, McElvaney OJ, Flannery R, Keenan J, Meleady P, Henry M, Clynes M, Gunaratnam C, McElvaney NG, Reeves EP: Inflammatory Induced ER Stress in Cystic Fibrosis Neutrophils is Reduced by Ivacaftor Treatment. Irish J Med Sci 2014;183:S519-S520.

7 Zheng Z, Zhang CB, Zhang K: Measurement of Er Stress Response and Inflammation in the Mouse Model of Nonalcoholic Fatty Liver Disease. Methods Enzymol 2011;489:329-348.

8 Okla M, Wang W, Kang I, Chung S: Inflammation Attenuates Adaptive Thermogenesis via Autophagy and ER Stress-Associated Mechanism. Faseb J 2015;29:405.

-9 Kaser A, Lee AH, Franke A, Glickman JN, Zeissig S, Tilg H, Nieuwenhuis EE, Higgins DE, Schreiber S, Glimcher LH, Blumberg RS: XBP1 links ER stress to intestinal inflammation and confers genetic risk for human inflammatory bowel disease. Cell 2008;134:743-756.

10 McGuckin MA, Eri RD, Das I, Lourie R, Florin TH: ER stress and the unfolded protein response in intestinal inflammation. Am J Physiol Gastrointest Liver Physiol 2010;298:G820-G832.

11 Sturn A, Harder-D’Heureuse J, Wiedenmann B, Dignass AU: Intestinal epithelial cells express functional interleukin-8-receptors. Gastroenterology 2003;124:A475-A475.

12 Kleinschek MA, Boniface K, Sadekova S, Grein J, Murphy EE, Turner SP, Raskin L, Desai B, Faubion WA, de Waal Malefyt R, Pierce RH, McClanahan T, Kastelein RA: Circulating and gut-resident human Th17 cells express CD161 and promote intestinal inflammation. J Exp Med 2009;206:525-534.

13 Gerlach K, Hwang Y, Nikolaev A, Atreya R, Dornhoff H, Steiner S, Lehr HA, Wirtz S, Vieth M5, Waisman A, Rosenbauer F, McKenzie AN, Weigmann B, Neurath MF: TH9 cells that express the transcription factor PU.1 drive T cell-mediated colitis via IL-9 receptor signaling in intestinal epithelial cells. Nat Immunol 2014;15:676-686.

14 Jiang Q, Chen S, Ren W, Liu G, Yao K, Wu G, Yin Y: Escherichia coli aggravates endoplasmic reticulum stress and triggers CHOP-dependent apoptosis in weaned pigs. Amino Acids 2017;49:2073-2082.

15 Dänicke S, Hegewald AK, Kahlert S, Kluess J, Rothkötter HJ, Breves G, Döll S: Studies on the toxicity of deoxynivalenol (DON), sodium metabisulfite, DON-sulfonate (DONS) and de-epoxy-DON for porcine peripheral blood mononuclear cells and the Intestinal Porcine Epithelial Cell lines IPEC-1 and IPEC-J2, and on effects of DON and DONS on piglets. Food Chem Toxicol 2010;48:2154-2162.

16 Liu F, Li G, Wen K, Bui T, Cao D, Zhang Y, Yuan L: Porcine small intestinal epithelial cell line (IPEC-J2) of rotavirus infection as a new model for the study of innate immune responses to rotaviruses and probiotics. Viral Immunol 2010;23:135-149.

17 Dänicke S, Valenta H, Ganter M, Brosig B, Kersten S, Diesing AK, Kahlert S, Panther P, Kluess J, Rothkötter HJ: Lipopolysaccharides (LPS) modulate the metabolism of deoxynivalenol (DON) in the pig. Mycotoxin Res 2014;30:161-170.

18 Arce C, Ramírez-Boo M, Lucena C, Garrido JJ: Innate immune activation of swine intestinal epithelial cell lines (IPEC-J2 and IPI-2I) in response to LPS from Salmonella typhimurium. Comp Immunol Microbiol Infect Dis 2010;33:161-174.

19 Paszti-Gere E, Matis G, Farkas O, Kulcsar A, Palocz O, Csiko G, Neogrady Z, Galfi P: The effects of intestinal LPS exposure on inflammatory responses in a porcine enterohepatic co-culture system. Inflammation 2014;37:247-260.

-20 Farkas O, Palócz O, Pászti-Gere E, Gálfi P: Polymethoxyflavone Apigenin-Trimethylether Suppresses LPSInduced Inflammatory Response in Nontransformed Porcine Intestinal Cell Line IPEC-J2 Oxid Med Cell Longev 2015; DOI:10.1155/2015/673847.

-21 Chen G, Fu S, Feng W, Huang B, Xu S, Wang W, Liu J: AMP010014A09 in Sus Scrofa Encodes an Analog of G Protein-Coupled Receptor 109A, Which Mediates the Anti-Inflammatory Effects of Beta-Hydroxybutyric Acid. Cell Physiol Biochem 2017;42:1420-1430.

22 Han C, Ding Z, Shi H, Qian W, Hou X, Lin R: The Role of Probiotics in Lipopolysaccharide-Induced Autophagy in Intestinal Epithelial Cells. Cell Physiol Biochem 2016;38:2464-2478.

23 McGuckin MA, Eri RD, Das I, Lourie R, Florin TH: Intestinal secretory cell ER stress and inflammation. Biochem Soc Trans 2011;39:1081-1085.

-24 Thomas SE, Malzer E, Ordóñez A, Dalton LE, van 't Wout EF, Liniker E, Crowther DC, Lomas DA, Marciniak SJ: p53 and Translation Attenuation Regulate Distinct Cell Cycle Checkpoints during Endoplasmic Reticulum (ER) Stress. J Biol Chem 2013;288:7606-7617. 


\section{Cellular Physiology Cell Physiol Biochem 2018;48:2441-2455 \begin{tabular}{l|l|l} 
and Biochemistry Published online: 16 August, 2018 & $\begin{array}{l}\text { @ } 2018 \text { The Author(s). Published by S. Karger AG, Basel } \\
\text { www.karger.com/cpb }\end{array}$ \\
\hline
\end{tabular}}

Jiang et al.: LPS Aggravates Apoptosis via Crosstalk Between GRP78 and P53

25 Dioufa N, Chatzistamou I, Farmaki E, Papavassiliou AG, Kiaris H: p53 antagonizes the unfolded protein response and inhibits ground glass hepatocyte development during endoplasmic reticulum stress. Exp Biol Med 2012;237:1173-1180.

-26 Edagawa M, Kawauchi J, Hirata M, Goshima H, Inoue M, Okamoto T, Murakami A, Maehara Y, Kitajima S: Role of Activating Transcription Factor 3 (ATF3) in Endoplasmic Reticulum (ER) Stress-induced Sensitization of p53-deficient Human Colon Cancer Cells to Tumor Necrosis Factor (TNF)-related Apoptosis-inducing Ligand (TRAIL)-mediated Apoptosis through Up-regulation of Death Receptor 5 (DR5) by Zerumbone and Celecoxib. J Biol Chem 2014;289:21544-21561.

-27 Cunha DA, Igoillo-Esteve M, Gurzov EN, Germano CM, Naamane N, Marhfour I, Fukaya M, Vanderwinden JM, Gysemans C, Mathieu C, Marselli L, Marchetti P, Harding HP, Ron D, Eizirik DL, Cnop M: Death Protein 5 and p53-Upregulated Modulator of Apoptosis Mediate the Endoplasmic Reticulum Stress-Mitochondrial Dialog Triggering Lipotoxic Rodent and Human beta-Cell Apoptosis. Diabetes 2012;61:2763-2775.

28 Lin WC, Chuang YC, Chang YS, Lai MD, Teng YN, Su IJ, Wang CC, Lee KH, Hung JH: Endoplasmic Reticulum Stress Stimulates p53 Expression through NF-kappa B Activation. PloS One 2012;7:e39120.

29 Li J, Lee B, Lee AS: Endoplasmic reticulum stress-induced apoptosis - Multiple pathways and activation of p53-up-regulated modulator of apoptosis (PUMA) and NOXA by p53 J Biol Chem 2006;281:7260-7270.

30 Lantto TA, Laakso I, Dorman HJ, Mauriala T, Hiltunen R, Kõks S, Raasmaja A: Cellular Stress and p53Associated Apoptosis by Juniperus communis L. Berry Extract Treatment in the Human SH-SY5Y Neuroblastoma Cells. Int J Mol Sci 2016;17:e1113.

-31 Zhao HX, Fu XS, Zhou XY, Chen X: Endoplasmic Reticulum Stress May Not Be Involved in Intestinal Epithelial Cell Apoptosis in Experimental Acute Pancreatitis. Dig Dis Sci 2015;60:1690-1698.

-32 Koh SJ, Kim JW, Kim BG, Lee KL, Chun J, Kim JS: Fexofenadine Regulates Nuclear Factor-kappa B Signaling and Endoplasmic Reticulum Stress in Intestinal Epithelial Cells and Ameliorates Acute and Chronic Colitis in Mice. J Pharmacol Exp Ther 2015;352:455-461.

33 Choi Y, Koh SJ, Lee HS, Kim JW, Gwan Kim B, Lee KL, Kim JS: Roxithromycin inhibits nuclear factor kappaB signaling and endoplasmic reticulum stress in intestinal epithelial cells, and ameliorates experimental colitis. Exp Biol Med 2014;8:S72-S73.

34 Fuhler G, Lie MR, Dimitrijevic P, Woude CJVD, Peppelenbosch M: Sa1824 Low Dose Naltrexone Reduces In vitro Endoplasmic Reticulum Stress and Stimulates Wound Healing in Intestinal Epithelial Cells. Gastroenterology 2016;150:S373-S373.

-35 Eri RD, Adams RJ, Tran TV, Tong H, Das I, Roche DK, Oancea I, Png CW, Jeffery PL, Radford-Smith GL, Cook MC, Florin TH, McGuckin MA: An intestinal epithelial defect conferring ER stress results in inflammation involving both innate and adaptive immunity. Mucosal Immunol 2011;4:354-364.

-36 Wu X, Sun L, Zha W, Studer E, Gurley E, Chen L, Wang X, Hylemon PB, Pandak WM Jr, Sanyal AJ, Zhang L, Wang G, Chen J, Wang JY, Zhou H: HIV Protease Inhibitors Induce Endoplasmic Reticulum Stress and Disrupt Barrier Integrity in Intestinal Epithelial Cells. Gastroenterology 2010;138:197-209.

-37 Beek MC, Ofman R, Dijkstra I, Wijburg F, Engelen M, Wanders R, Kemp S: Lipid-induced endoplasmic reticulum stress in X-linked adrenoleukodystrophy. Biochim Biophys Acta 2017;1863:2255-2265.

-38 Choi Y, Koh SJ, Lee HS, Kim JW, Gwan Kim B, Lee KL, Kim JS: Roxithromycin inhibits nuclear factor kappaB signaling and endoplasmic reticulum stress in intestinal epithelial cells and ameliorates experimental colitis in mice. Exp Biol Med 2015;240:1664-1671.

39 Berger E, Haller D: Structure-function analysis of the tertiary bile acid TUDCA for the resolution of endoplasmic reticulum stress in intestinal epithelial cells: Biochem Biophys Res Commun 2011;409:610615.

40 Ji Y, Wu Z, Dai Z, Sun K, Zhang Q, Wu G: Excessive L-cysteine induces vacuole-like cell death by activating endoplasmic reticulum stress and mitogen-activated protein kinase signaling in intestinal porcine epithelial cells. Amino Acids 2016;48:149-156.

41 Yuan L, Cao Y, Knochel W: Endoplasmic reticulum stress induced by tunicamycin disables germ layer formation in Xenopus laevis embryos. Dev Dyn 2007;236:2844-2851.

42 Wu Z, Li M, Huango ACJ, Jia X, Li Y: Effects of serum containing natural cerebrolysin on glucose-regulated protein 78 and CCAAT enhancer-binding protein homologous protein expression in neuronal PC12 cells following tunicamycin-induced endoplasmic reticulum stress. Neural Regen Res 2009;4:92-97. 


\section{Cellular Physiology Cell Physiol Biochem 2018;48:2441-2455 \begin{tabular}{ll|l} 
and Biochemistry Published online: 16 August, 2018 & $\begin{array}{l}\text { (c) } 2018 \text { The Author(s). Published by S. Karger AG, Basel } \\
\text { www.karger.com/cpb }\end{array}$
\end{tabular}}

43 Wu ZZ, Li YH, Andrew CJ, Li HM, Zhang XL, Wang JG, Yang M, Chen MY: Endoplasmic Reticulum Stress Induced by Tunicamycin and Antagonistic Effect of Tiantai No.1 on Mesenchymal Stem Cells. Chin J Integr Med 2010;16:41-49.

44 Kawada K, Iekumo T, Saito R, Kaneko M, Mimori S, Nomura Y, Okuma Y: Aberrant neuronal differentiation and inhibition of dendrite outgrowth resulting from endoplasmic reticulum stress. J Neurosci Res 2014;92:1122-1133.

45 Suganya N, Bhakkiyalakshmi E, Suriyanarayanan S, Paulmurugan R, Ramkumar KM: Quercetin ameliorates tunicamycin-induced endoplasmic reticulum stress in endothelial cells. Cell Prolif 2014;47:231-240.

-46 Fan L, Sun G, Ma T, Zhong F, Lei Y, Li X, Wei W: Melatonin reverses tunicamycin-induced endoplasmic reticulum stress in human hepatocellular carcinoma cells and improves cytotoxic response to doxorubicin by increasing CHOP and decreasing Survivin. J Pineal Res 2013;55:184-194.

47 Shen MZ, Ding MG, Wang B: Dids Exerts a Cardioprotective Effect on Tunicamycin-Induced Apoptosis Via Reduction of Endoplasmic Reticulum Stress. Heart 2011;97:A55.

-48 Chung H, Chung HY, Bae CW, Kim CJ, Park S: Ghrelin suppresses tunicamycin- or thapsigargin-triggered endoplasmic reticulum stress-mediated apoptosis in primary cultured rat cortical neuronal cells. Endocr J 2011;58:409-420.

49 Heo JR, Lee GA, Kim GS, Hwang KA, Choi KC: Phytochemical-induced reactive oxygen species and endoplasmic reticulum stress-mediated apoptosis and differentiation in malignant melanoma cells. Phytomedicine 2018;39:100-110.

50 Kim SR, Kim HJ, Kim DI, Lee KB, Park HJ, Jeong JS, Cho SH, Lee YC: The interrelationship between IL-17 and ER stress in LPS-induced lung inflammation. Allergy 2013;68:2-3.

51 Verfaillie T, Garg AD, Agostinis P: Targeting ER stress induced apoptosis and inflammation in cancer. Cancer Lett 2013;332:249-264.

52 Bae EY, Lee SW, Seong S, Cho W, Ahn JS, Cho HS: Inhibitory Effects of Verrucarin A on Tunicamycin-Induced ER Stress in FaO Rat Liver Cells. Molecules 2015;20:8988-8996.

53 Jiang Q, He L, Hou Y, Chen J, Duan Y, Deng D, Wu G, Yin Y, Yao K: Alpha-ketoglutarate enhances milk protein synthesis by porcine mammary epithelial cells. Amino Acids 2016;48:2179-2188.

54 Ringseis R, Kynast AM, Couturier A, Most E, Eder K: Ingestion of frying fat leads to activation of the endoplasmic reticulum stress-induced unfolded protein response in the duodenal mucosa of pigs. Mol Nutr Food Res 2016;60:957-963.

55 Hu P, Han Z, Couvillon AD, Kaufman RJ, Exton JH: Autocrine tumor necrosis factor alpha links endoplasmic reticulum stress to the membrane death receptor pathway through IRE1alpha-mediated NF-kappaB activation and down-regulation of TRAF2 expression. Mol Cell Biol 2006;26:3071-3084.

-56 Deng J, Lu PD, Zhang Y, Scheuner D, Kaufman RJ, Sonenberg N, Harding HP, Ron D: Translational repression mediates activation of nuclear factor kappa B by phosphorylated translation initiation factor 2 Mol Cell Biol 2004;24:10161-10168.

-57 Shkoda A, Ruiz PA, Daniel H, Kim SC, Rogler G, Sartor RB, Haller D: Interleukin 10 blocked endoplasmic reticulum stress in intestinal epithelial cells: impact on chronic inflammation. Gastroenterology 2017;132:190-207.

-58 Pahl HL, Baeuerle PA: A Novel Signal-Transduction Pathway from the Endoplasmic-Reticulum to the Nucleus Is Mediated by Transcription Factor Nf-Kappa-B. Embo J 1995;14:2580-2588.

59 Verhaar R, Drukarch B, Bol JG, Jongenelen CA, Musters RJ, Wilhelmus MM: Increase in endoplasmic reticulum-associated tissue transglutaminase and enzymatic activation in a cellular model of Parkinson's disease. Neurobiol Dis 2012;45:839-850.

60 Kim HJ, Jeong JS, Kim SR, Park SY, Chae HJ, Lee YC: Inhibition of endoplasmic reticulum stress alleviates lipopolysaccharide-induced lung inflammation through modulation of NF- $\mathrm{B} / \mathrm{HIF}-1 \alpha$ signaling pathway. Sci Rep 2012;3:1142-1151.

61 Wadgaonkar R, Phelps KM, Haque Z, Williams AJ, Silverman ES, Collins T: CREB-binding protein is a nuclear integrator of nuclear factor-kappa B and p53 signaling. J Biol Chem 1999;274:1879-1882. 